УДК: 616.33-002.44-084

\title{
T.H. Муратова
}

\section{Влияние леветирацетама и диазепама на пенициллин-индуцированную очаговую эпилептическую активность} Одесский национальный медицинский университет

Ключевые слова: диазепам, пенициллин $G$, противосудорожные средства, эпилепсия.

В острых экспериментах на крысах линии Вистар (44 животных) исследовали показатели мощности эпилептических очагов и длительность их существования в условиях внутрибрюшинного применения леветирацетама (ЛВР, 30,0 и 130,0 мг/кг) и диазепама $(0,5$ и 1,5 мг/кг). Под влиянием ЛВР наблюдалось достоверное угнетение пенициллин-вызванной (15000 МЕ/мл) очаговой активности, которая регистрировалась на 120 (на 26,8 \%) и 30 мин (на 48,4 \%) с момента применения препарата в дозах 30,0 и 130,0 мг/кг соответственно. Диазепам $(0,5$ и 1,5 мг/кг), вводимый на высоте очаговой эпилептической активности, ее редуцировал на 15 и 5 мин соответственно на 41,4 и на 46,8 \%. Через 5 мин с момента введения диазепама (1,5 мг/кг), примененного на фоне (за 30 мин) ЛВР $(30,0$ мг/кг), отмечалось уменьшение мощности очаговой активности в 3,7 раза в сравнении с группой контроля $($ Р $<0,05)$. Длительность существования очаговой активности в условиях совместного применения ЛВР и диазепама уменьшалась до $110,5 \pm 11,2$ мин с $270,5 \pm$ 24,5 в группе контроля $(\mathrm{P}<0,05)$.

\section{Вплив леветирацетаму та діазепаму на пеніцилін-індуковані осередки епілептичної активності}

\section{T.М. Муратова}

У гострих експериментах на щурах лінії Вістар (44 тварини) досліджували показники потужності епілептичних осередків та тривалість їх існування за умов внутрішньоочеревинного застосування леветирацетаму (ЛВР, 30,0 i 130,0 мг/кг) i діазепаму (0,5 і 1,5 мг/кг). Під впливом ЛВР спостерігалось вірогідне пригнічення пеніцилін-викликаної (15000 МО/мл) осередкової активності, що реєструвалась на 120 (на 26,8 \%) і 30 хв (на 48,4 \%) з моменту застосування препарату дозами 30,0 і 130,0 мг/кг відповідно. Діазепам (0,5 і 1,5 мг/кг), який застосовували на висоті осередкової епілептичної активності, ії редукував на 15 та 5 хв відповідно на 41,4 і 46,8 \%. Через 5 хв із моменту застосування діазепаму (1,5 мг/кг), котрий вводили на тлі (за 30 хв) застосування ЛВР (30,0 мг/кг, в/очер.), виявлялось зменшення потужності осередкової активності в 3,7 раза в порівнянні з групою контролю $(\mathrm{P}<0,05)$. Тривалість наявності осередкової активності за умов сумісного застосування ЛВР і діазепаму редукувалась до $110,5 \pm 11,2$ хв $3270,5 \pm 24,5$ у групі контролю (Р $<0,05)$.

Ключові слова: діазепам, пеніцилін $G$, протисудомні засоби, епілепсія.

Запорізький медичний журнал. - 2014. - №6 (87). - С. 71-75

\section{The influence of levetiracteam and diazepam on penicillin-induced focal epileptic activity}

T.N. Muratova

Aim. The power of epileptic foci and their life-span in Wistar rats (44 animals) were investigated under conditions of levetiracetam ( 30,0 and $130,0 \mathrm{mg} / \mathrm{kg}$, i.p. $)$ and diazepam $(0,5$ and $1,5 \mathrm{mg} / \mathrm{kg}$, i.p. $)$ treatment in acute experiments.

Methods and results. Penicillin - induced (15.000 IU/ml) epileptic foci in rat's cortex were suppressed by levetiracetam $(30,0 \mathrm{and} 130 \mathrm{mg} / \mathrm{kg}$, i.p. $)$ with the net reduction of focal epileptic power registered in 120 (by 26,8\%) and $30 \mathrm{~min}$ (by 48,4\%) from the moment of epileptogen application correspondently. Diazepam $(0,5$ and $1,5 \mathrm{mg} / \mathrm{kg}$, i.p.) being administered at the height of focal epileptoigenesis, reduced focal activity in 15,0 and 5,0 min by 41,4 and 46,8\% correspondently. In 5,0 min from the moment of diazepam administration (1,5 mg/kg, i.p.), which was made after preliminary (in $30 \mathrm{~min}$ ) treatment with LVR (30,0 mg/kg, i.p.) was followed by 3,7 times reduction of power of focal epileptic activity, when compared with control group $(\mathrm{P}<0,05)$

Conclusion. The life-span of focal activity under conditions of combined usage of LVR and diazepam was reduced up to 110,5+11,2 min from 270,5+24,5 min in control group $(\mathrm{P}<0,05)$.

Key words: Diazepam, Penicillin $G$, Anticonvulsants, Epilepsy.

Zaporozhye medical journal 2014; №6 (87): 71-75

Современные нейропатофизиологические представления об эпилепсии диктуют сегодня изменение подходов к ее лечению. Учитывая, что эпилепсия представляет собой проявление структурно-функциональных перестроек в мозге, затрагивающих многочисленные центры и подсистемы с ближними и дальними связями, а возникновение припадков и внеприступных психоневрологических проявлений обусловлено сложными нейронными сетями, которые регулируют индивидуальные варианты течения заболевания, предпочтительным является выбор, с учетом эффективности, скорости титрования дозы, лекарственной формы, побочных явлений и стоимости, препарата или комбинации препаратов с широким спектром действия, что помогают при любых типах припадков и формах эпилепсии [1]. В качестве первого выбора для лечения генерализованных эпилепсий приоритетными среди препаратов с широким спектром действия являются вальпроаты, леветирацетам, ламотриджин, топирамат, бензодиазепины. Однако они не лишены нежелательных эффектов, в связи с чем целесообразным зачастую является их комбинация, позволяющая повысить эффективность противоэпилептической терапии за счет воздействия на различные звенья патогенеза эпилепсии, снизить дозу, минимизировать нежелательные проявления медикаментозного лечения. В этом плане привлекают внимание леветирацетам (ЛВР) в комбинации с диазепамом. Выбор ЛВР обусловлен тем, что он является уникальным по своим разносторонним механизмам противоэпилептического действия $[3,4,13]$. 
Кроме того, предполагается, что в отличие от большинства других противоэпилептических препаратов он не просто подавляет эпилептическую активность в мозге, но может препятствовать ее возникновению и прогрессированию [4, 13]. К тому же ЛВР обладает такими побочными эффектами, как эмоциональная неустойчивость, нервозность, агрессивность, инсомния и др., вследствие чего может быть целесообразной его комбинация с классическим антиконвульсантом и транквилизатором диазепамом. Следует подчеркнуть, что ранее на модели эпилептического статуса, индуцируемого электрическими стимуляциями волокон перфорантного пути у крыс, показано усиление противосудорожных эффектов ЛВР на фоне применения диазепама [2]. В клинической практике также установлено повышение противосудорожной эффективности препаратов при их сочетанном применении [11].

Сегодня в нейропатофизилогии и нейрофармакологии применяется большое количество моделей эпилепсии, которые, с одной стороны, позволяют установить механизм противоэпилептического действия препарата, но, с другой стороны, создают проблему «неуспешности» противоэпилептической терапии в клинической практике, не отражая многообразия клинических форм данной патологии. Так, ЛВР не показал эффективности в обычных классических моделях острых судорог, вызванных рядом химических агентов, максимальным электрошоком и др. [1]. В связи с этим актуальным является проведение дальнейших исследований совместного применения противоэпилептических препаратов на разных моделях эпилептической активности и отличающихся от уже установленных механизмов действия этих соединений. Учитывая отсутствие прямого воздействия ЛВР на ГАМК-рецепторы, представляет интерес изучение возможности усиления противосудорожных эффектов на очаговой форме эпилепсии, индуцированной пенициллином, эпилептогенное действие которого связано с нарушением ГАМК-ергического тормозного контроля возбудимости нейронов [9].

\section{Цель работы}

Оценка эффективности совместного применения ЛВР и диазепама на модели очаговой эпилепсии, индуцируемой в коре головного мозга бензилпенициллином.

\section{Материал и методы исследования}

Исследования выполнены в условиях острого эксперимента на 44 крысах-самцах линии Вистар массой 270-320 г, которые содержались в стандартных условиях вивария ОНМедУ. В каждой группе наблюдения было не менее 7 животных. Эксперименты проводили в соответствии с требованиями GLP и комиссии биоэтики ОНМедУ (протокол № 84 от 10 октября 2008 г.). Материалы статьи одобрены комиссией по биоэтике ОНМедУ.

В условиях эфирного рауш-наркоза животным осуществляли трахеостомию, фиксацию в стереотаксическом аппарате СЭЖ-5, трепанацию черепа. Внутрибрюшинным (в,бр) введением d-тубокурарина (0,25 мг/кг) («Orion», Финляндия) животных переводили на искусственное дыхание. Наблюдение начинали через 2,5 ч с момента прекращения эфирного наркоза. Все точки сдавления тканей и края операционной раны инфильтрировали 0,25 \% раствором новокаина, повторяли каждые 30-40 мин.

ЛВР (30,0 и 130,0 мг/кг, «UCB», Бельгия) применяли в/бр, приготавливая взвесь в Твине-80. Препарат применяли за 30 мин до в/бр введения диазепама (0,5 и 1,5 мг/кг, «Weimer Pharma, GmbH», ФРГ). Животным контрольной группы осуществляли в/бр применение аналогичного объема Твина- 80 .

После вскрытия твердой мозговой оболочки с помощью аппликации на фронтальные отделы коры головного мозга фильтровальной бумажки ( 2 х2 мм), смоченной в свежеприготовленном растворе натриевой соли бензилпенициллина (15 000 ME/мл), создавали очаг эпилептической активности (ЭпА). Активность очага ЭпА регистрировали с помощью компьютерного электроэнцефалографа «DX-5000» (Харьков, Украина) монополярно, для чего индифферентный электрод крепили в носовых костях черепа.

ЭпА очагов выражали в условных единицах, приняв за 1 единицу среднюю амплитуду в 1,0 мВ при частоте генерирования разрядов 1 в минуту. Для оценки уровня ЭпА брали эпоху генерирования разрядов длительностью 1 мин; время существования очагов определяли от первого до последнего спайка [5].

Результаты исследований обрабатывались статистически с применением метода ANOVA и критерия Neuman-Keuls. B качестве достоверных различий принимались значения $\mathrm{P}<0,05$.

\section{Результаты и их обсуждение}

В группе контроля (8 крыс) через 3-7 мин с момента нанесения раствора бензилпенициллина (15000 МЕ/Мл) в зоне аппликации отмечалось возникновение первых спайковых разрядов, амплитуда и частота которых в условиях продолжающейся аппликации возрастали в течение последующих 10-15 мин наблюдения, достигая величин соответственно $1,2-2,0$ мВ и 25-45 разрядов в мин. Через 20 мин с момента нанесения эпилептогена мощность очагов составила $65,3+10,3$ усл.ед. Устойчивая ЭпА отмечалась в течение последующих 20-45 мин, после чего на протяжении от 30 мин до 3,5 ч происходило снижение частоты и амплитуды генерирования разрядов и их исчезновение. Общая длительность существования очагов составила $270,5 \pm 24,5$ мин.

1. Эффекты леветирацетама. На фоне применения ЛВР (30,0 мг/кг, в/бр за 30 мин до аппликации раствора бензилпенициллина натрия на кору головного мозга, 7 крыс) нанесение раствора эпилептогена вызывало появление первых спайковых потенциалов через 4-9 мин с момента аппликации. На протяжении 10,5-17,5 мин последующего наблюдения отмечалось увеличение частоты и амплитуды разрядов до 1,1-1,8 мВ и 25-40 разряда в мин. На высоте активности очагов их мощность составила $54,6 \pm 8,5$ усл. ед. Устойчивая ЭпА в очагах регистрировалась на протяжении 25-50 мин, после чего в течение от 25 мин до 3,7 ч происходило снижение частотно-амплитудных характеристик и отмечалось полное угнетение активности очагов. Следует подчеркнуть, что через 120 мин с момента появления разрядов в очагах их мощность была меньшей в сравнении с таковой в группе контроля на 26,8 \% $(\mathrm{P}<0,05)$ и статистически достоверные различия между группами сохранялись до конца наблюдения (рис. 1). Общая продолжительность существования очагов составила $255,8 \pm 23,4$ мин $(\mathrm{P}>0,05)$. 


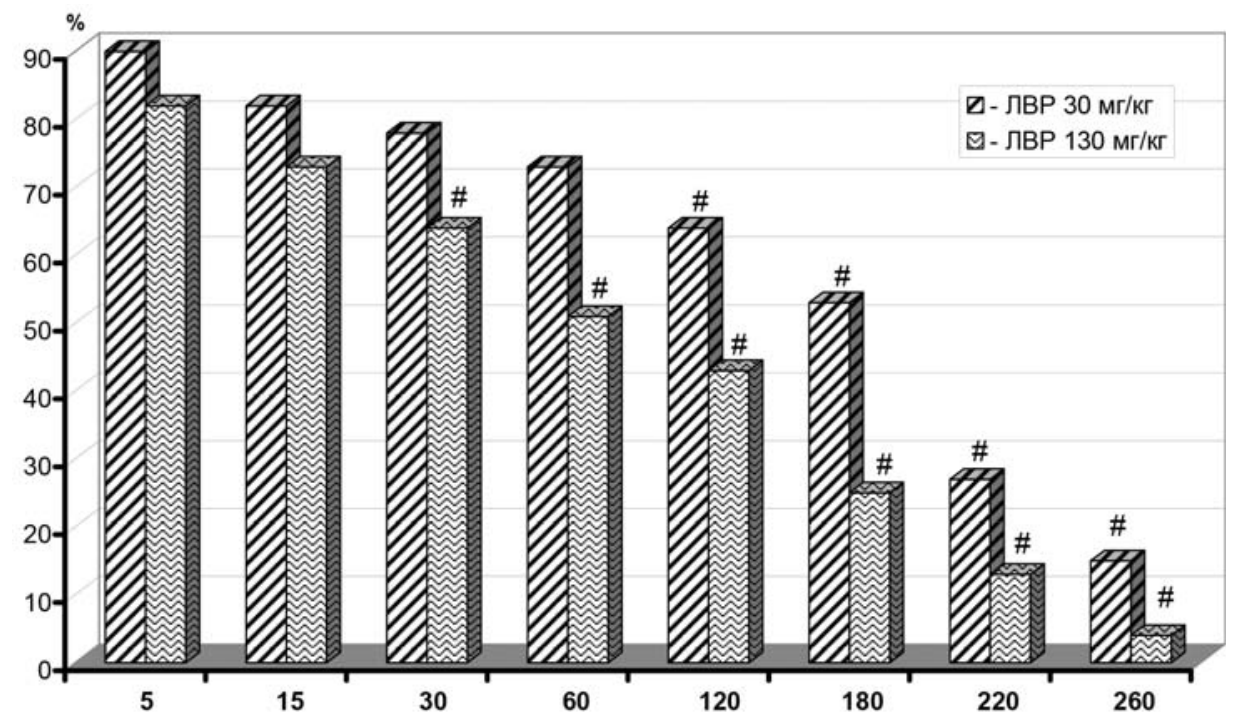

Puc. 1. Влияние леветирацетама на активность эпилепических очагов в коре головного мозга.

Примечания: по оси абцисс - время с момента появления разрядов в очатах (минуты), по оси ординат - мощность очагов в \% по отношению к таковой в группе контроля, принятой за $100 \%$; \# - $<<0,05$ в сравнении с аналогичным показателем в группе контроля (ANOVA+ Newman-Keuls тест).

На фоне применения ЛВР в большей из исследованных доз (130,0 мг/кг, в/бр, 8 крыс) аппликация раствора натриевой соли бензилпенициллина (15000 МЕ/мл) сопровождалась появлением первых спайковых потенциалов через 5,5-15,0 мин с момента нанесения эпилептогена на кору головного мозга. Нарастание амплитуды и частота спайковых разрядов до максимальных значений (0,9-1,7 мВ и 20-42 разряда в мин соответственно) отмечалось на протяжении 15-20 мин наблюдения и на высоте активности

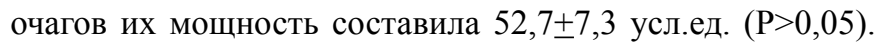
Устойчивая активность в очагах регистрировалась на протяжении 15-35 мин, после чего на протяжении от 45 мин до 3,0 ч происходило постепенное уменьшение амплитуды и частоты спайковых разрядов и отмечалось их полное исчезновение. Следует подчеркнуть, что уже через 30 мин с

момента появления спайковых потенциалов их мощность была меньше таковой в группе контроля на 48,4\% $\%(\mathrm{P}<0,05)$. Достоверные отличия с группой контроля сохранялись до конца наблюдения (рис. 1). Общая продолжительность существования очаговой ЭпА составила 236,2+19,7 мин $(\mathrm{P}>0,05)$.

2. Эффекты диазепама. Введение диазепама (0,5 мг/ кг, в/бр, 7 крыс), произведенное через 15 мин с момента возникновения потенциалов в очаге (15000 ME/мл), сопровождалось снижением мощности очаговой активности (на $14,7 \%$ в в сравнении с таковой в группе контроля уже через 5 мин с момента инъекции (Р>0,05) (рис. 2). Через 15 мин мощность очагов снижалась на 41,4 \%, что было достоверно меньше, чем в контроле $(\mathrm{P}<0,05)$. Достоверные отличия между группами сохранялись до конца наблюдения, а общая длительность существования очагов составила 217,5+14,3

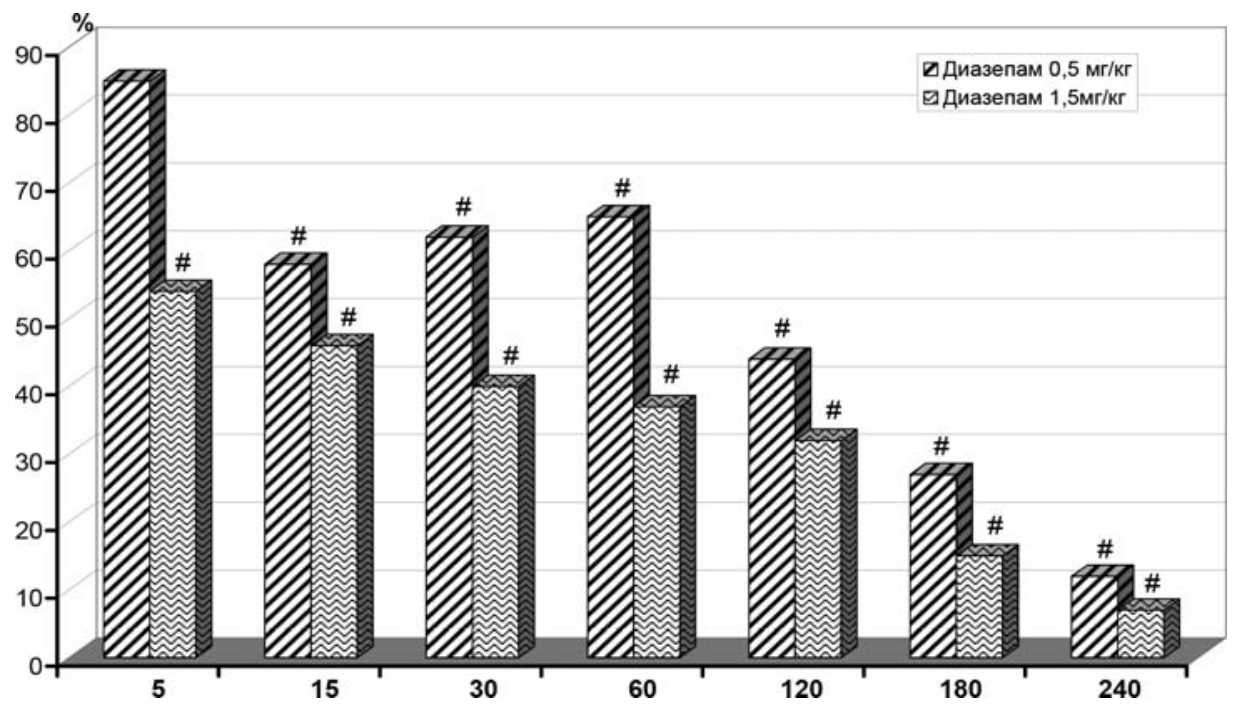

Puc. 2. Влияние диазепама на активность эпилептических очагов в коре головного мозга.

Примечания: по оси абсцисс - время с момента в/бр применения диазепама (мин); по оси ординат - мощность очагов в \% по отношению к контролю, принятому за $100 \%$. \# - P $<0,05$ в сравнении с соответствующим показателем в группе контроля (ANOVA+ Neuman-Keuls).

() Т.Н. Муратова, 2014 


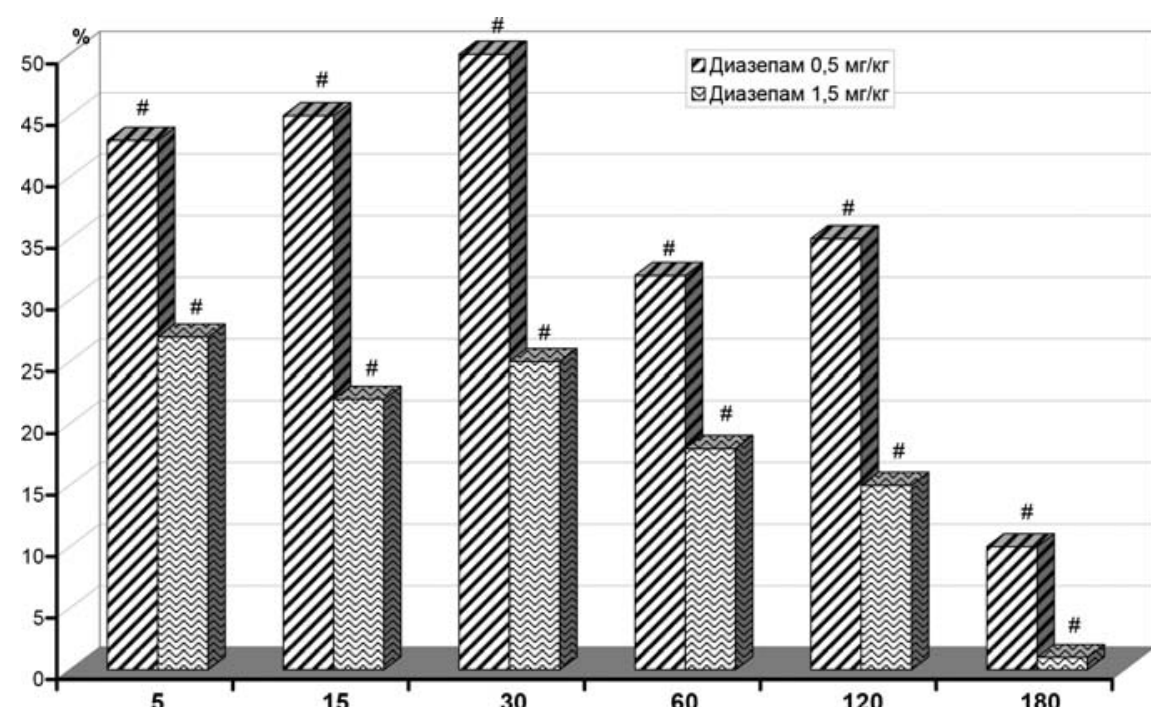

Puc. 3. Эффекты диазепама на пенициллин-вызванные (15000 ME/мл) очаги эпилептической активности в коре головного мозга крыс в условиях предварительного применения леветирацетама (30,0 мг/кг, в/бр).

Примечания: по оси абсцисс - время с момента в/бр применения диазепама (мин); по оси ординат - мощность очагов в \% по отношению к контролю, принятому за $100 \%$. \# - P<0,05 в сравнении с соответствующим показателем в группе контроля (ANOVA+ Neuman-Keuls).

мин, что не отличалось от соответствующего показателя в контрольной группе животных (Р>0,05). Применение диазепама в большей дозе (1,5 мг/кг, в/бр, 7 крыс) вызывало значительное снижение мощности очагов уже через 5 мин с момента инъекции (на 46,8 \%) по сравнению с контролем $(\mathrm{P}<0,05)$ (рис.2). Достоверные различия сохранялись до конца наблюдения, а общая длительность существования очагов составила $189,6 \pm 13,4$ мин и также не отличалась от показателя в контроле $(\mathrm{P}>0,05)$.

3. Эффекты сочетанного применения леветирацетама и диазепама. Применение диазепама (0,5 мг/кг, в/бр, 8 крыс), осуществленное через 15 мин с момента возникновения первых спайковых разрядов и через 45 мин с момента в/ бр введения ЛВР (30,0 мг/кг, в/бр), вызывало уже через 5 мин после инъекции значительное и достоверное снижение мощности очагов (на 58,4 \%) в сравнении с контролем (рис. 3). Указанные достоверные различия между группами отмечались до конца наблюдения. При этом следует отметить, что через 30 мин с момента применения диазепама мощность очагов $(11,4 \pm 1,5$ усл.ед.) была также меньше таковой в группе с самостоятельным введением аналогичной дозы диазепама $(22,5+2,1$ усл. ед.) $(\mathrm{P}<0,05)$, и достоверные различия показателя мощности очагов в указанных группах также сохранялись до конца наблюдения. Длительность существования очагов составила $159,4+12,7$ мин, что не отличалось от аналогичного показателя в контроле $(\mathrm{P}>0,05)$.

Под влиянием диазепама (1,5 мг/кг, в/бр, 9 крыс) мощность очагов ЭпА через 5 мин с момента введения препарата и через 35 мин после в/бр применения ЛВР в дозе 30,0 мг/ кг была меньше таковой в контроле в 3,7 раза $(\mathrm{P}<0,05)$ (рис. 3). Достоверные различия исследуемого показателя между группами сохранялись до конца наблюдения. Через 15 мин с момента введения диазепама мощность очагов $(8,8 \pm 1,7$ усл. ед.) была достоверно меньшей, чем в группе животных с самостоятельным применением аналогичной дозы диазепама $(17,4 \pm 2,3$ усл. ед.) $(\mathrm{P}<0,05)$. Достоверные различия между группами также сохранялись до конца наблюдения. Длительность существования очагов в условиях сочетанного применения ЛВР (30,0 мг/кг, в/бр) и диазепама (1,5 мг/кг, в/бр) составила 110,5+11,2 мин, что было меньше как в сравнении с группой контроля, так и в сравнении с животными, которым вводили только диазепам $(\mathrm{P}<0,05)$.

Таким образом, полученные данные свидетельствуют о том, что в условиях формирования в коре головного мозга крыс очагов ЭпА, генерирующих интериктальную (спайковую) активность, применение как леветирацетама, так и диазепама оказывает дозозависимое противоэпилептическое действие, что согласуется с данными других авторов $[3,7]$. Под влиянием препаратов происходит уменьшение частоты, амплитуды спайковых разрядов, а также снижение длительности существования очагов.

Усиление противосудорожного действия препаратов при совместном применении может быть связано с реализацией механизмов, обеспечивающих формирование эффекта снижения возбудимости нейрональной мембраны. В этом отношении следует отметить, что одним из возможных механизмов осуществления противосудорожного действия ЛВР является его способность связываться с синаптическим везикулярным протеином 2A (SV2A) и, как следствие, вызывать непрямое торможение пресинаптического высвобождения нейромедиаторов [8]. Кроме того, ЛВР оказывает модулирующие эффекты на внутриклеточное содержание ионов кальция путем повышения их высвобождения из внутриклеточных депо [12], а также за счет торможения кальциевых каналов $\mathrm{N}$-типа [10]. Также установлено, что ЛВР оказывает антагонистическое влияние на отрицательную аллостерическую модуляцию ионами цинка и Љ-карболинов ГАМК- и глицин-индуцированных трансмембранных токов [6]. Подобные мембранотропные эффекты ЛВР, по-видимому, могут эффективно дополнять влияние диазепама на хлор-ионофор ГАМК-рецепторов мембраны нейрона. 
Принимая во внимание, что фармакологическая резистентность развивается к большинству противоэпилептических препаратов, за исключением ЛВР [3, 4, 9], установленный эффект взаимного потенцирования противосудорожного действия ЛВР и диазепама возможно применить к коррекции толерантности к действию диазепама, в том числе и его желательной и нежелательной активности.

\section{Выводы}

1. Леветирацетам и диазепам оказывают дозозависимое

\section{Список литературы}

1. Зенков Л.Р. Генерализованные эпилепсии: современные концепции и терапевтические подходы / Л.Р. Зенков // Неврология, нейропсихиатрия, психосоматика. - 2012. - №1. - C. $72-82$.

2. Anticonvulsant effects of levetiracetam and levetiracetamdiazepam combinations in experimental status epilepticus / A.M. Mazarati, R. Baldwin, H. Klitgaard et al. // Epilepsy Res. - 2004. - Vol.58. - №2-3. - P. 167-174.

3. Czapinski P. Mechanisms of Action of Antiepileptic Drugs / P. Czapinski, B. Blaszczyk, S.J. Czuczwar // Current Topics in Medicinal Chemistry. - 2005. - Vol. 5. - P. 3-14.

4. De Smedt T. Levetiracetam: the profile of a novel anticonvulsant drug-part I: preclinical data / T. De Smedt, R. Raedt, K. Vonck, P Boon // CNS Drug Rev. - 2007. - №13. - P. 3-56.

5. Effect of levetiracetam on penicillin induced epileptic activity in rats / A.E. Arık, F. Bağırıcı, F. Sefil, C. Marangoz // Acta Neurobiol. Exp. - 2014. - Vol. 74. - P. 266-275.

6. 6. The antiepileptic drug levetiracetam reverses the inhibition by negative allosteric modulators of neuronal GABA- and glycinegated currents / J.M. Rigo, G. Hans, L. Nquyen et al. // Br. J. Pharmacol. - 2002. - Vol. 136. - P. 659-672.

7. The maximal electroshock seizures (MES) model in the preclinical assesment of potential new antiepileptic drugs / M.M. CastelBranco, G.L. Alves, I.V. Figueiredo et al. // Methods Find. Exp. Clin. Pharmacol. - 2009. - Vol. 31. - №2. - P. 101-106.

8. The synaptic vesicle glycoprotein $2 \mathrm{~A}$ ligand levetiracetam inhibits presynaptic $\mathrm{Ca} 2+$ channels through an intracellular pathway / C. Vogl, S. Mochida, C. Wolff et al. // Mol. Pharmacol. - 2012. - Vol. 82. - P. 199-208.

9. Loescher W. Critical review of current animal models of seizures and epilepsy used in the discovery and development of new antiepileptic drugs / W. Loscher // Seizure. - 2011. - Vol. 20. P. 359-368.

10. Lukyanetz E.A. Selective blockade of N-type calcium channels by levetiracetam / E.A. Lukyanetz, V.M. Shkryl, P.G. Kostyuk // Epilepsia. - 2002. - Vol. 43. - P. 9-18.

11. Modur P.N. Sequential intrarectal diazepam and intravenous levetiracetam in treating acute repetitive and prolonged seizures / P.N. Modur, W.E. Miller, S. Zhang // Epilepsia. -2010. - Vol. 51. - №6. - P. 1078-1082.

12. Nagarkatti N. Levetiracetam inhibits both ryanodine and IP3 receptor activated calcium induced calcium release in hippocampal neurons in culture / N. Nagarkatti, L.S. Deshpande, R.J. DeLorenzo // Neurosci. Lett. - 2008. - Vol. 436. - P. 289-293.

13. Neurocognitive effects of brivaracetam, levetiracetam, and lorazepam / K.J. Meador, A. Gevins, P.T. Leese et al. // Epilepsia. - 2011. - Vol. 52. - №2. - P. 264-272. тормозное противосудорожное действие на пенициллин-индуцированной очаговой модели эпилептической активности.

2. Сочетанное применение леветирацетама и диазепама сопровождается развитием потенцированного противосудорожного действия препаратов.

Перспективы дальнейших исследований предполагают разработку рекомендаций клинического сочетанного применения диазепама и леветирацетама у пациентов с простыми парциальными формами эпилепсии.

\section{References}

1. Zenkov, L. R. (2012) Generalizovannye e’pilepsii: sovremennye koncepcii i terapevticheskie podkhody [Generalized epilepsy: contemporary conceptions and therapeutical approaches]. Nevrologiya, nejropsikhiatriya, psikhosomatika, 1, 72-82. [in Russian].

2. Mazarati, A. M., Baldwin, R., Klitgaard, H., et al. (2004) Anticonvulsant effects of levetiracetam and levetiracetam-diazepam combinations in experimental status epilepticus. Epilepsy Res., $58(2-3), 167-174$.

3. Czapinski, P., Blaszczyk, B., \& Czuczwar, S. J. (2005) Mechanisms of Action of Antiepileptic Drugs. Current Topics in Medicinal Chemistry, 5, 3-14.

4. De Smedt, T., Raedt, R., Vonck, K., \& Boon, P. (2007) Levetiracetam: the profile of a novel anticonvulsant drug-part I: preclinical data. CNS Drug Rev., 13, 3-56.

5. Arık, A. E., Bağırıcı, F., Sefil, F., \& Marangoz, C. (2014) Effect of levetiracetam on penicillin induced epileptic activity in rats. Acta Neurobiol. Exp, 74, 266-275.

6. Rigo, J. M., Hans, G., Nquyen, L., et al. (2002) The antiepileptic drug levetiracetam reverses the inhibition by negative allosteric modulators of neuronal GABA- and glycine-gated currents. Br. J. Pharmacol., 136, 659-672. doi: 10.1038/sj.bjp.0704766.

7. Castel-Branco, M. M., Alves, G. L., Figueiredo, I. V. et al. (2009) The maximal electroshock seizures (MES) model in the preclinical assesment of potential new antiepileptic drugs. Methods Find. Exp. Clin. Pharmacol., 31(2), 101-106. doi: 10.1358/ mf.2009.31.2.1338414

8. Vogl, C., Mochida, S., Wolff, C. et al. (2012) The synaptic vesicle glycoprotein 2A ligand levetiracetam inhibits presynaptic $\mathrm{Ca} 2+$ channels through an intracellular pathway. Mol. Pharmacol., 82, 199-208. doi: 10.1124/mol.111.076687.

9. Loescher, W. (2011) Critical review of current animal models of seizures and epilepsy used in the discovery and development of new antiepileptic drugs. Seizure, 20, 359-368. doi: 10.1016/j. seizure.2011.01.003.

10. Lukyanetz, E. A. Shkryl, V. M., \& Kostyuk, P. G. (2002) Selective blockade of N-type calcium channels by levetiracetam. Epilepsia, 43, 9-18. doi: 10.1046/j.1528-1157.2002.24501.x.

11. Modur, P. N., Miller, W. E., \& Zhang, S. (2010) Sequential intrarectal diazepam and intravenous levetiracetam in treating acute repetitive and prolonged seizures. Epilepsia, 51(6), 10781082. doi: 10.1111/j.1528-1167.2009.02385.x.

12. Nagarkatti, N., Deshpande, L. S., \& DeLorenzo, R. J. (2008) Levetiracetam inhibits both ryanodine and IP3 receptor activated calcium induced calcium release in hippocampal neurons in culture. Neurosci. Lett., 436, 289-293. doi: 10.1016/j.neulet.2008.02.076.

13. Meador, K. J., Gevin, A., Leese, P. T., et al. (2011) Neurocognitive effects of brivaracetam, levetiracetam, and lorazepam. Epilepsia, 52(2), 264-272. doi: 10.1111/j.1528-1167.2010.02746.x.

Сведения об авторе:

Муратова Т. Н., к. мед. н., доцент, зав. каф. неврологии, Одесский национальный медицинский университет,

E-mail: godlevsky@odmu.edu.ua. 